\title{
Comparative Study between Radiofrequency Ablation Combined with either Percutaneous Ethanol Injection or Percutaneous Acetic Acid Injection in the Management of Hepatocellular Carcinoma.
}

\author{
Mohamed Alaa EI Din Nouh ${ }^{\mathbf{1}}$, Mohamed Kamal El Sharkawy ${ }^{2}$, \\ Gamal Saad EI Deeb ${ }^{1}$ and Haytham Mohamed Mohamed Azab ${ }^{1}$ \\ ${ }^{1}$ Tropical Medicine department, Faculty of Medicine, Menoufia University, Egypt \\ ${ }^{2}$ Radiodiology department, Faculty of Medicine, Al-Azhar University, Cairo, Egypt.
}

Corresponding Author Haytham Mohamed Mohamed Azab

Mobile:

$+201288887889$

E mail:

HMazab@hotmail.co. $u k$

Key words: Radiofrequency Ablation; Percutaneous Ethanol Injection;

Percutaneous Acetic Acid Injection;

Hepatocellular

Carcinoma
Background and study aim: Radiofrequency ablation (RFA) has attracted the greatest interest because of its effectiveness and safety. However, complete tumor necrosis rate with RFA for tumors larger than $5 \mathrm{~cm}$ is less favorable. Acetic acid, which has the ability to penetrate cells with the property of extracting collagen and dissolving lipids, has a stronger killing effect on hepatocytes than ethanol. The aim of this study was to compare two percutaneous combined therapies, RFA plus percutaneous ethanol injection (PEI) and RFA plus percutaneous acetic acid injection (PAI) in hepatocellular carcinoma (HCC) treatment in patients having single focal lesions more than five and up to seven $\mathrm{cm}$ in diameter.

Patients and Methods: The patients were selected according to the triphasic CT scanning characteristics of HCC. They were randomly allocated into 2 groups: GI included 30 patients who were candidates for 1 setting of RFA then PEI in the same setting. GII included 30 patients ; they were ablated by 1 setting of RFA with 2 overlaps to decrease the size of the remaining unablated areas, then PAI in the same setting.

Results: Evaluation of the response one month later using triphasic CT showed significant better responses in GII compared to GI $(83.3 \%$ vs $60 \%)$ with $\mathrm{P}$ value $<0.05$. The response 3 months later was not changed significantly compared to the response after one month of the procedure $(56.7 \%$ in GI and $80 \%$ in GII)

Conclusion: Ablation of inoperable large HCC $5.1-7 \mathrm{~cm}$ can be done with combined techniques. RFA plus acetic acid was compared to RFA plus ethyl alcohol. Complete ablation was superior when acetic acid was used.

\section{INTRODUCTION}

HCC is the fifth most common neoplasm globally and the second most common cause of cancer-related death by the World Health Organization. The predomination of liver cancer is greater than 2:1 in male-to-female gender. In 2012, almost $83 \%$ of the estimated 782,000 HCC cases showed in less developed regions. East, South Asia and sub-Saharan Africa are the regions of highest incidence, whereas in Southern Europe and North America are the regions of the intermediate incidence, while Northern Europe and South-Central Asia being the regions of lowest incidence [1]. HCV and HBV are the most common precipitating factors in $\mathrm{HCC}$ development. $\mathrm{HCV}$ has affected around $12 \%$ of the Egyptian population leading to cirrhosis in about $20 \%$. In such patient HCC develops in about $15 \%$ of the cases [5]. In order to decide the appropriate therapeutic choice, the accurate diagnosis of neoplastic lesions by one or more of the imaging modalities is mandatory. This imaging workup has two purposes; lesion characterization and cancer staging [2]. Often, once HCC has been 
detected, it is difficult to treat due to chemoresistance, multicentric incidence and underlying poor hepatic reserve, which in itself leads to a high mortality rate [3]. Surgery offers the only real chance of cure, but the majority has an unresectable disease because of tumor stage or liver cirrhosis [4]. Local ablation is a safe and effective therapy for patients who cannot undergo resection or as a palliative treatment before transplantation [5]. Among the various local percutaneous ablative therapies, radio-frequency ablation (RFA) has attracted the greatest interest because of its effectiveness and safety in the treatment of small HCCs, with $62 \%$ - 68\%, a 3-year survival rate, and related morbidity and mortality rates of $0 \%-12 \%$ and $0 \%-1 \%$ respectively. Although, less favorable results of complete tumor necrosis rate with RFA occurs in tumors larger than $5 \mathrm{~cm}$ in diameter, while the local recurrence rate can be as high as $20 \%$, even for HCCs less than $3.5 \mathrm{~cm}$ in diameter [6]. Thus, to improve RFA results, the ablation zone needs to be extended, so that larger tumors can be treated and local recurrences of smaller tumors after treatment can be decreased [7]. Acetic acid, which has the ability to penetrate cells with the property of extracting collagen and dissolving lipids, has a stronger killing effect on hepatocytes than ethanol [8]. PEI is also effective in ablating small tumors [9].

The aim of the present study was to evaluate and compare two percutaneous combined therapies, RFA plus PEI and RFA plus PAI in HCC treatment in patients having single focal lesions more than 5 and up to $7 \mathrm{~cm}$ in diameter.

\section{PATIENTS AND METHODS}

This prospective study was conducted on 60 patients with compensated HCC who had single lesion $5 \mathrm{~cm}$ and up to $7 \mathrm{~cm}$ in diameter, they were Child A according to Child Pugh classification. Their ages ranged from 46 to 77 . They were managed at RFA unit of Tropical Medicine Department, Al-Azhar University Hospitals from April 2014 to January 2017. Ethical approval was taken for conducting this study and written consents were obtained. The patients were selected according to the triphasic CT scanning characteristics of HCC (early uptake of the dye in the arterial and rapid washout in venous and delayed phases). They were randomly allocated into 2 groups: GI included 30 patients who were candidates for 1 setting of RFA then PEI in the same setting. Their mean age was 60.7 (Table 1).
GII included 30 patients. They were ablated by 1 setting of RFA with 2 overlaps to decrease the size of the remaining unablated areas, then PAI in the same setting. Their mean age was 58.1 (Table 1). According to the lesion size, each group was subdivided into 2 subgroups: GA which included 15 patients who had lesions 5.1 to $6 \mathrm{~cm}$ in maximum diameter and GB which included 15 patients who had lesions 6.1 to $7 \mathrm{~cm}$ in maximum diameter. All patients were subjected to preprocedure work up including full history, thorough clinical examination, and detailed investigations. This was followed by performing triphasic CT scanning and Alpha-fetoprotein (AFP) 1 month and 3 months later. The results were compared to decide if one regimen was better than the other.

\section{Statistical analysis:}

Data were analyzed using Statistical Program for Social Science (SPSS) version 20.0. Quantitative data were expressed as mean \pm standard deviation (SD). Qualitative data were expressed as frequency and percentage. The following tests were done: Independent-samples t-test of significance was used when comparing the two means, Chi-square (X2) test of significance was used in order to compare proportions between two qualitative parameters and Probability (P-value). P-value $<0.05$ was considered significant, $\mathrm{P}$-value $<0.001$ was considered as highly significant and P-value $>0.05$ was considered insignificant.

\section{RESULTS}

This study was conducted on 60 patients having single focal $\mathrm{HCC}$, ranging from 5.1 to $7 \mathrm{~cm}$ in diameter. The mean age of the patients was 60.30. It was 60.70 for GI and 58.16 for GII. They $51(85 \%)$ males and $9(15 \%)$ females. GI composed of 26 males $(86.7 \%)$ and 4 females (13.3\%). GII composed of 25 males $(83.3 \%)$ and 5 females $(16.7 \%)$. The studied patients included 13 smokers $(22 \%)$ as $6(20 \%)$ in GI and 7 $(23.3 \%)$ in GII (Table 1). No significant statistical difference was detected between the two groups. $\mathrm{HCV} \mathrm{Ab}$ was positive in $54(90 \%)$ patients, 26 $(8.7 \%)$ for $\mathrm{GI}$ and $28(93.3 \%)$. HBs $\mathrm{Ag}$ was positive in one patient in GI. Combined infection was seen in $3(10 \%)$ patients of GI and $2(6.7 \%)$ patients of GII (Table 2). No significant statistical difference was detected between the two groups. AFP was positive in $44(73.3 \%)$ patients, 23 (7.6\%) in GI and $21(70 \%)$ in GII (Table 3). The difference was not significant between the

Nouh et al., Afro-Egypt J Infect Endem Dis 2019;9(2):129-138

https://aeji.journals.ekb.eg/

http://mis.zu.edu.eg/ajied/home.aspx 
groups. When AFP levels were compared after one month of ablation a significant drop was observed. However, no further drop was noted 3 months later (Table 4). Evaluation of the response one month later using triphasic CT showed significant better responses in GII compared to GI $(83.3 \%$ vs $60 \%)$ with $\mathrm{P}$ value $<0.05$. The response 3 months later was not changed significantly compared to the response after one month of the procedure $(56.7 \%$ in GI and $80 \%$ in GII) (Table 5,6). When the groups were subdivided into two subgroups A and B. Subgroups GI A showed better results when compared to GI B (66.7\% vs $53.3 \%$ ). However, this did not reach a significant value after 1 month of ablation ( $\mathrm{P}$ $>0.05$ ) (Table 9). This was also observed 3 months later (Table 10). Comparing subgroups GII A to GII B better results were in favor to GII A (Table11 \&12). However, it did not reach a significant value $(\mathrm{P}<0.05)$. Comparing subgroup GI A to GII A (66.7\% vs $86.6 \%)$ significantly better response was noted in GII. Comparing subgroup GI B to GII B (46.6 vs $73.3 \%$ ) significantly better response was observed in GII B. The Complications reported were abdominal pain and fever. This was noted in $63.3 \%$ of patients, $60 \%$ in GI and $66.7 \%$ in GII. The difference was not significant. Fever was observed in $26.6 \%$ of patients, $23.3 \%$ for GI and $30 \%$ for GII. The difference was also not significant (Table 13). The results indicate significantly better responses when acetic acid was combined to RFA.

Table (1): Demographic features of the studied groups

\begin{tabular}{|l|c|c|c|c|c|}
\hline & Group I & Group II & Total & $\mathbf{t} / \mathbf{x}^{2}$ & P \\
\hline Age (year) & & & & & \\
Mean & 60.70 & 58.16 & 60.30 & 1.223 & $>0.05$ \\
SD & 8.55 & 7.51 & 8.58 & & \\
Range & $46-77$ & $48-73$ & $46-77$ & & \\
\hline Sex & & & & & \\
Male & $26(86.7 \%)$ & $25(83.3 \%)$ & $51(85 \%)$ & 0.084 & $>0.05$ \\
Female & $4(13.3 \%)$ & $5(16.7 \%)$ & $9(15 \%)$ & & \\
M: F ratio & $7: 1$ & $5: 1$ & $6: 1$ & & \\
\hline Smoking & & & & & \\
Smoker & $6(20 \%)$ & $7(23.3 \%)$ & $13(22 \%)$ & 0.004 & $>0.05$ \\
Non- smoker & $24(80 \%)$ & $23(76.7 \%)$ & $47(78 \%)$ & & \\
\hline
\end{tabular}

There is no significant difference of the mean values between the studied groups.

Table (2): Prevalence of HCV-Ab and HBsAg among the studied groups

\begin{tabular}{|l|c|c|c|c|c|}
\hline & Group I & Group II & Total & $\mathbf{X}^{2}$ & P \\
\hline $\mathrm{HCV} \mathrm{Ab}$ & $26(86.7 \%)$ & $28(93.3 \%)$ & $54(90 \%)$ & 1.884 & $>0.05$ \\
\hline $\mathrm{HbsAg}$ & $1(3.3 \%)$ & $0(0 \%)$ & $1(1.7 \%)$ & 2.472 & $>0.05$ \\
\hline $\mathrm{HCV} \mathrm{Ab}$ and $\mathrm{HbsAg}$ & $3(10 \%)$ & $2(6.7 \%)$ & $5(8.3 \%)$ & 0.324 & $>0.05$ \\
\hline
\end{tabular}

There is no significant difference of the mean values between the studied groups.

Table (3): Comparison between the studied groups as regard AFP values before treatment (cut-off value $200 \mathrm{ng} / \mathrm{ml}$ )

\begin{tabular}{|c|c|c|c|c|c|}
\hline AFP(ng/ml) & Group I & Group II & Total & \multirow{3}{*}{$\mathbf{T}$} & \multirow{3}{*}{$\mathbf{P}$} \\
\hline Positive & $23(76.6 \%)$ & $21(70 \%)$ & $44(73.3 \%)$ & & \\
\hline Negative & $7(23.3 \%)$ & $9(3 \%)$ & $16(26.6 \%)$ & & \\
\hline $\begin{array}{l}\text { Mean } \pm \text { SD } \\
\text { Range }\end{array}$ & $\begin{array}{r}781.46 \pm 667.27 \\
118.0-2965.0\end{array}$ & $\begin{array}{c}575.00 \pm 406.86 \\
103.0-1382.0\end{array}$ & $\begin{array}{l}662.16 \pm 563.16 \\
103.0-2965.0\end{array}$ & 1.683 & $>0.05$ \\
\hline
\end{tabular}

There is no significant difference of the mean values between the studied groups.

Nouh et al., Afro-Egypt J Infect Endem Dis 2019; 9(2):129-138

https://aeji.journals.ekb.eg/

http://mis.zu.edu.eg/ajied/home.aspx 
Table (4): Comparison between AFP values before treatment, 1 and 3 months after treatment

\begin{tabular}{|l|c|c|c|c|c|}
\hline \multirow{2}{*}{} & Group I & Group II & \multirow{2}{*}{ Total } & \multirow{2}{*}{ T } & P \\
\cline { 2 - 4 } & Mean \pm S. D & Mean \pm S. D & & & \\
\hline Before treatment & $781.46 \pm 667.27$ & $575.00 \pm 406.86$ & $678.23 \pm 537.065$ & 5.363 & $>0.05$ \\
\hline 1 month after & $246.26 \pm 164.46$ & $342.83 \pm 237.87$ & $294.545 \pm 201.165$ & 0.609 & $<0.05$ \\
\hline 3 months after & $223.40 \pm 128.42$ & $318.90 \pm 196.45$ & $271.15 \pm 162.435$ & 0.425 & $>0.05$ \\
\hline
\end{tabular}

There is a significant difference of the mean values between the studied groups after 1 months after treatment.

Table (5): Comparison between two procedures for HCC ablation in two groups of patients $5.1-7 \mathrm{~cm}$ in maximum diameter based on triphasic CT 1 month after ablation

\begin{tabular}{|l|c|c|c|c|c|}
\hline \multirow{2}{*}{\multicolumn{1}{c|}{ Response }} & Group I & Group II & \multirow{2}{*}{ Total } & \multirow{2}{*}{$\mathbf{x}^{\mathbf{2}}$} & \multirow{2}{*}{ p-value } \\
\cline { 2 - 3 } & $(\mathbf{n = 3 0})$ & $(\mathbf{n = 3 0})$ & & \multirow{2}{*}{4.955} & $<0.05$ \\
\hline Complete ablation & $18(60 \%)$ & $25(83.3 \%)$ & $43(71.6 \%)$ & $<$ \\
\hline Incomplete ablation & $12(40 \%)$ & $5(16.7 \%)$ & $17(28.3 \%)$ & & \\
\hline
\end{tabular}

There is a significant difference of the mean values between the studied groups.

Table (6): Comparison of two procedures for HCC ablation in two groups of patients $5.1-7 \mathrm{~cm}$ in maximum diameter based on triphasic CT 3 months after ablation

\begin{tabular}{|c|c|c|c|c|c|}
\hline \multirow{2}{*}{ Response } & Group I & Group II & \multirow{2}{*}{ Total } & \multirow{2}{*}{$\mathbf{x}^{2}$} & \multirow{2}{*}{ p-value } \\
\hline & $(n=30)$ & $(\mathrm{n}=30)$ & & & \\
\hline Complete ablation & $17(56.7 \%)$ & $24(80 \%)$ & $41(68.3 \%)$ & \multirow{2}{*}{4.274} & \multirow{2}{*}{$<0.05$} \\
\hline Incomplete ablation & $13(43.3 \%)$ & $6(20 \%)$ & $19(31.6 \%)$ & & \\
\hline
\end{tabular}

There is a significant difference of the mean values between the studied groups.

Table (7): Comparison of two procedures for HCC ablation in subgroups of patients $5.1-6 \mathrm{~cm}$ in maximum diameter based on triphasic $\mathrm{CT}$ after 3 months

\begin{tabular}{|l|c|c|c|c|}
\hline \multirow{2}{*}{ Response } & $\begin{array}{c}\text { Group (I) } \\
\text { Subgroup A }\end{array}$ & $\begin{array}{c}\text { Group (II) } \\
\text { Subgroup A }\end{array}$ & \multirow{2}{*}{$\mathbf{x}^{\mathbf{2}}$} & \multirow{2}{*}{ p-value } \\
\cline { 2 - 3 } & $(\mathbf{n = 1 5 )}$ & $(\mathbf{n = 1 5})$ & & \\
\hline Complete ablation & $10(66.7 \%)$ & $13(86.6 \%)$ & \multirow{2}{*}{4.065} & $<0.05$ \\
\hline Incomplete ablation & $5(33.3 \%)$ & $2(13.3 \%)$ & \\
\hline
\end{tabular}

There is a significant difference of the mean values between the studied groups.

Table (8): Comparison of two procedures for HCC ablation in subgroups of patients $6.1-7 \mathrm{~cm}$ in maximum diameter based on triphasic CT after 3 months

\begin{tabular}{|c|c|c|c|c|}
\hline \multirow[t]{2}{*}{ Response } & $\begin{array}{c}\text { Group (I) } \\
\text { Subgroup B }\end{array}$ & $\begin{array}{c}\text { Group (II) } \\
\text { Subgroup B }\end{array}$ & \multirow[t]{2}{*}{$\mathbf{x}^{2}$} & \multirow[t]{2}{*}{ p-value } \\
\hline & $(n=15)$ & $(n=15)$ & & \\
\hline Complete ablation & $7(46.7 \%)$ & $12(80 \%)$ & \multirow{2}{*}{4.218} & \multirow{2}{*}{$<0.05$} \\
\hline Incomplete ablation & $8(53.3 \%)$ & $3(20 \%)$ & & \\
\hline
\end{tabular}

There is a significant difference of the mean values between the studied groups 
Table (9): Comparison of the response between the two subgroups of G I after 1 month

\begin{tabular}{|l|c|c|c|c|c|}
\hline \multirow{2}{*}{ Response } & G I A (5.1-6) & G I B (6.1-7) & \multirow{2}{*}{ Total } & \multirow{2}{*}{$\mathbf{x}^{2}$} & \multirow{2}{*}{ p-value } \\
\cline { 2 - 4 } & $(\mathbf{n = 1 5})$ & $(\mathbf{n = 1 5})$ & & \multirow{2}{*}{0.540} & $>0.05$ \\
\hline Complete ablation & $10(66.7 \%)$ & $8(53.3 \%)$ & $18(60 \%)$ & $12(40 \%)$ & \\
\hline Incomplete ablation & $5(33.3 \%)$ & $7(46.6 \%)$ & $12 \%$ & \\
\hline
\end{tabular}

This table shows no statistically significant difference between the two subgroups.

Table (10): Comparison of the response between the two subgroups of G I after 3 months

\begin{tabular}{|c|c|c|c|c|c|}
\hline \multirow{2}{*}{ Response } & G I A (5.1-6) & G I B (6.1-7) & \multirow{2}{*}{ Total } & \multirow{2}{*}{$x^{2}$} & \multirow{2}{*}{ p-value } \\
\hline & $(n=15)$ & $(n=15)$ & & & \\
\hline Complete ablation & $10(66.7 \%)$ & $7(46.6 \%)$ & $17(56.6 \%)$ & \multirow{2}{*}{0.564} & \multirow{2}{*}{$>0.05$} \\
\hline Incomplete ablation & $5(33.3 \%)$ & $8(53.3 \%)$ & $13(43.3 \%)$ & & \\
\hline
\end{tabular}

This table shows no statistically significant difference between the two subgroups.

Table (11): Comparison of the response between the two subgroups of G II after 1 month

\begin{tabular}{|c|c|c|c|c|c|}
\hline \multirow{2}{*}{ Response } & $\begin{array}{c}\text { GII A } \\
(5.1-6) \mathrm{cm}\end{array}$ & $\begin{array}{c}\text { GII B } \\
(6.1-7) \mathrm{cm}\end{array}$ & \multirow{2}{*}{ Total } & \multirow[t]{2}{*}{$\mathbf{x}^{2}$} & \multirow{2}{*}{ p-value } \\
\hline & $(n=15)$ & $(n=15)$ & & & \\
\hline Complete ablation & $13(86.6 \%)$ & $12(80 \%)$ & $25(83.3 \%)$ & \multirow{2}{*}{0.099} & \multirow{2}{*}{$>0.05$} \\
\hline Incomplete ablation & $2(13.3 \%)$ & $3(20 \%)$ & $5(16.7 \%)$ & & \\
\hline
\end{tabular}

This table shows no statistically significant difference between the two subgroups. Complete ablation was detected in $83.3 \%$ of the cases after 1 month.

Table (12): Comparison of the response between the two subgroups of G II after 3 months

\begin{tabular}{|c|c|c|c|c|c|}
\hline \multirow[t]{2}{*}{ Response } & $\begin{array}{c}\text { GII A } \\
(5.1-6) \mathrm{cm}\end{array}$ & $\begin{array}{c}\text { GII B } \\
(6.1-7) \mathrm{cm}\end{array}$ & \multirow[t]{2}{*}{ Total } & \multirow[t]{2}{*}{$\mathbf{x}^{2}$} & \multirow[t]{2}{*}{ p-value } \\
\hline & $(n=15)$ & $(n=15)$ & & & \\
\hline Complete ablation & $13(86.6 \%)$ & $11(73.3 \%)$ & $24(80 \%)$ & \multirow{2}{*}{0.095} & \multirow{2}{*}{$>0.05$} \\
\hline Incomplete ablation & $2(13.3 \%)$ & $4(26.7 \%)$ & $6(20 \%)$ & & \\
\hline
\end{tabular}

This table shows no statistically significant difference between the two subgroups.

Table (13): Comparison between both groups in post-procedural complications

\begin{tabular}{|l|c|c|c|c|c|}
\hline \multirow{2}{*}{ Response } & GI & GII & \multirow{2}{*}{ Total } & \multirow{2}{*}{$\mathbf{x}^{\mathbf{2}}$} & \multirow{2}{*}{ p-value } \\
\cline { 2 - 3 } & $\mathbf{( n = 3 0 )}$ & $\mathbf{( n = 3 0 )}$ & & \multirow{2}{*}{1.087} & \multirow{2}{*}{$>0.05$} \\
\hline Abdominal pain & $18(60 \%)$ & $20(66.7 \%)$ & $38(63.3 \%)$ & \multirow{2}{*}{$16(26.6 \%)$} & \\
\hline Fever & $7(23.3 \%)$ & $9(30 \%)$ & $16 \%$ &
\end{tabular}

This table shows no statistically significant difference between the two subgroups 


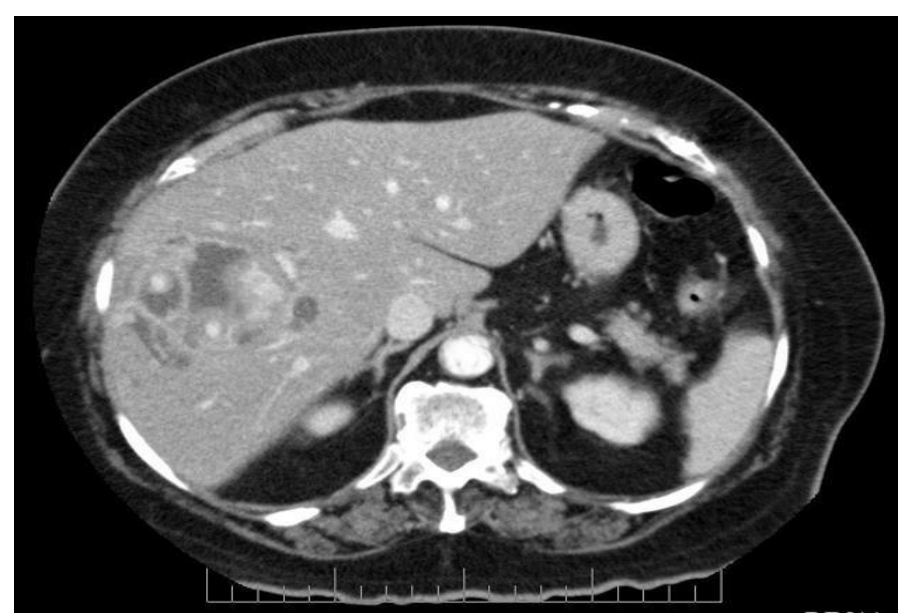

Figure (1): Triphasic CT; arterial phase, shows early enhanced well-defined HCC measuring about $6.5 \times 5 \mathrm{~cm}$ in diameter in the right hepatic lobe.

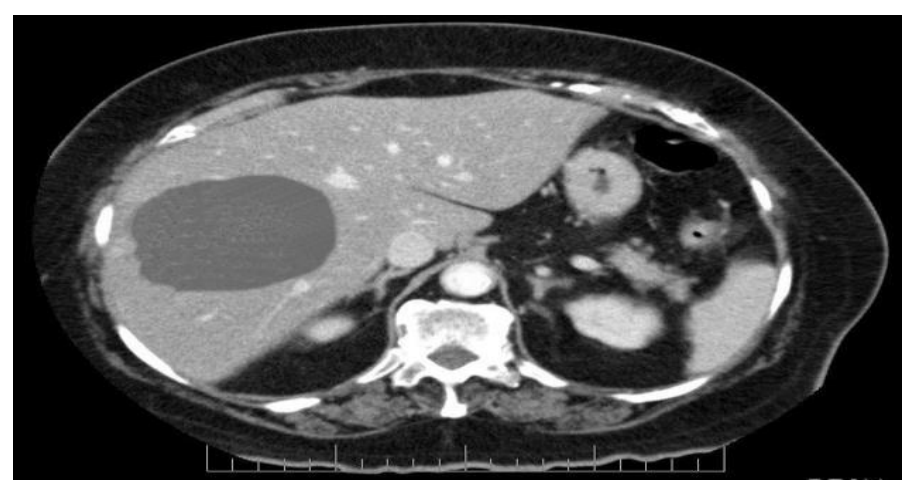

Figure (2): Follow up CT scan 1-month post RFA+PAI shows a well-defined hypodense lesion in the site of the ablated tumor $(6.5 \times 5 \mathrm{~cm})$ which does not enhance in the arterial phase.

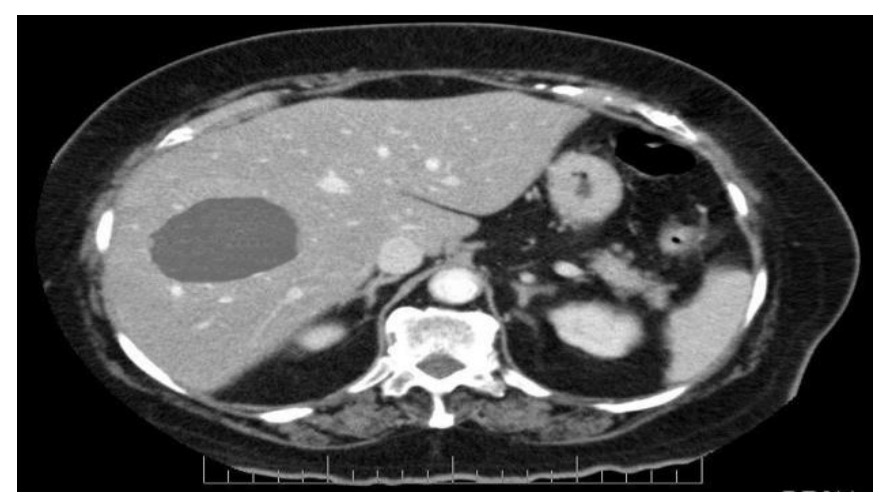

Figure (3): Follow up CT scan 3- months post RFA+PAI, decrease in the size of the lesion with complete ablation which does not enhance in the arterial phase. 

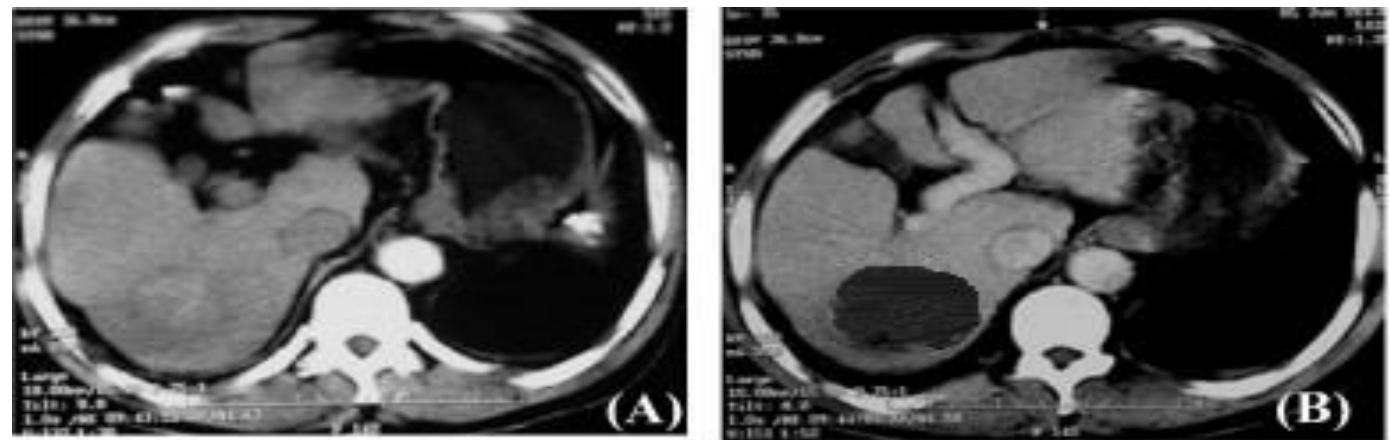

\section{Pre-ablation}
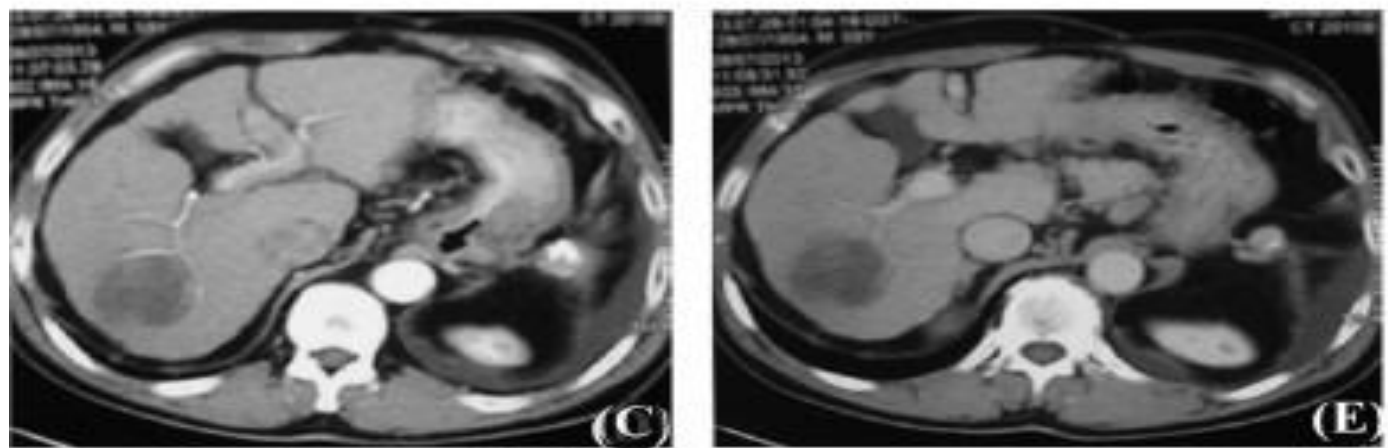

\section{One month post-ablation}
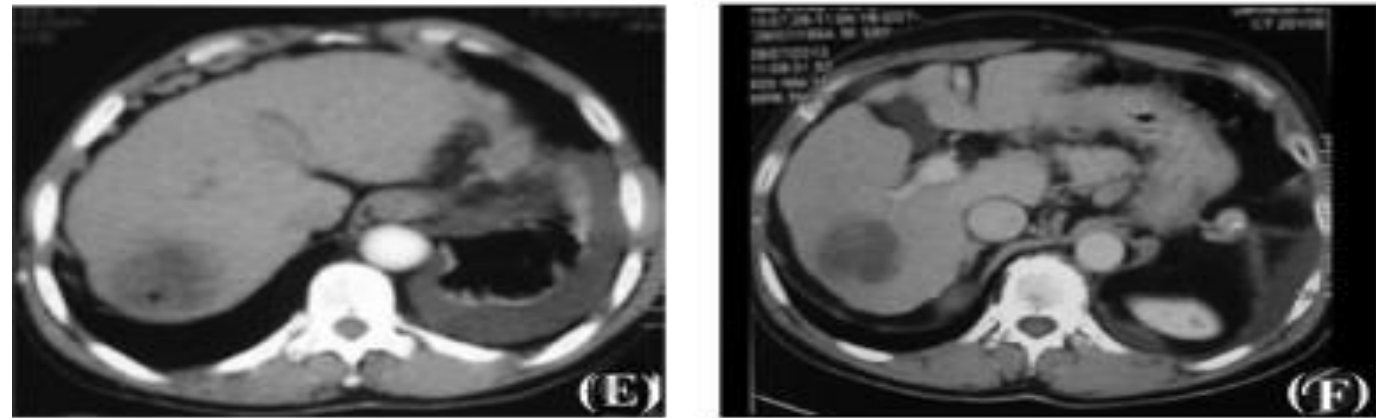

3 -monthpost-ablation

Figure (4): Triphasic ('T; arterial phase on left and delayed phase on right, shows early enhanced well-defined HCC measuring about $6 \times 5 \mathrm{~cm}$ in the right hepatic lobe. 1-month and 3-month post ablation using RFA+PAI shows complete ablation.
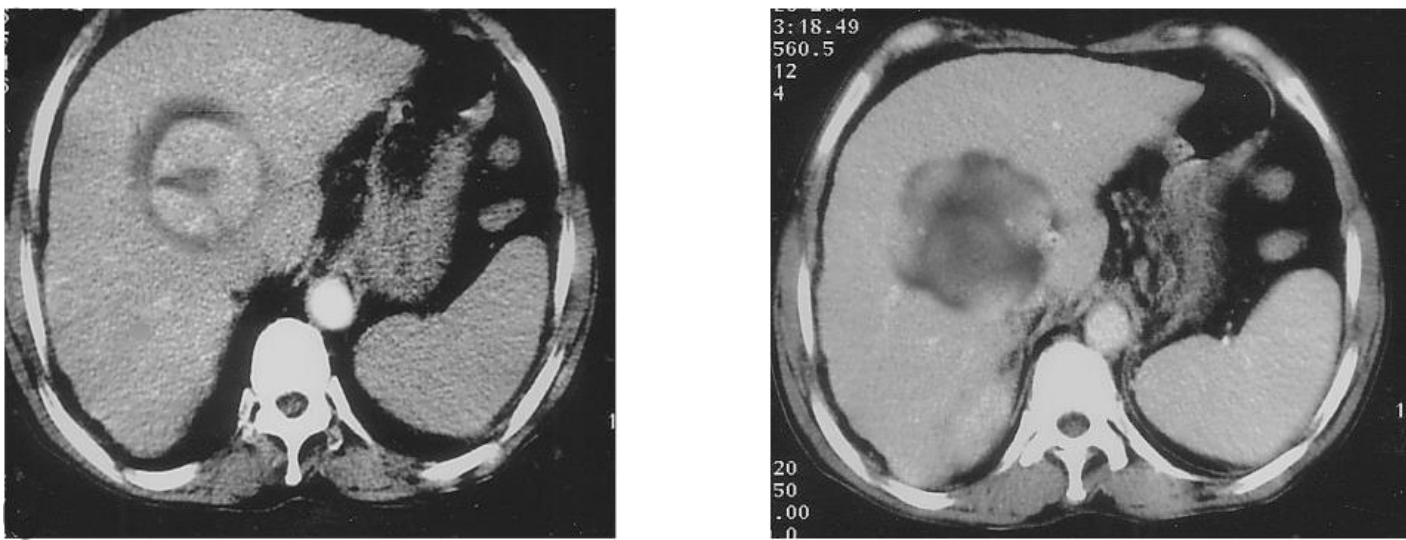

Figure (5): Triphasic CT scan (left) pre RFA+PEI shows a HCC $(5.4 \times 5.2 \mathrm{~cm})$. The 3 -months CT scan (right) shows partial ablation of the lesion.

Nouh et al., Afro-Egypt J Infect Endem Dis 2019; 9(2):129-138

https://aeji.journals.ekb.eg/

http://mis.zu.edu.eg/ajied/home.aspx 

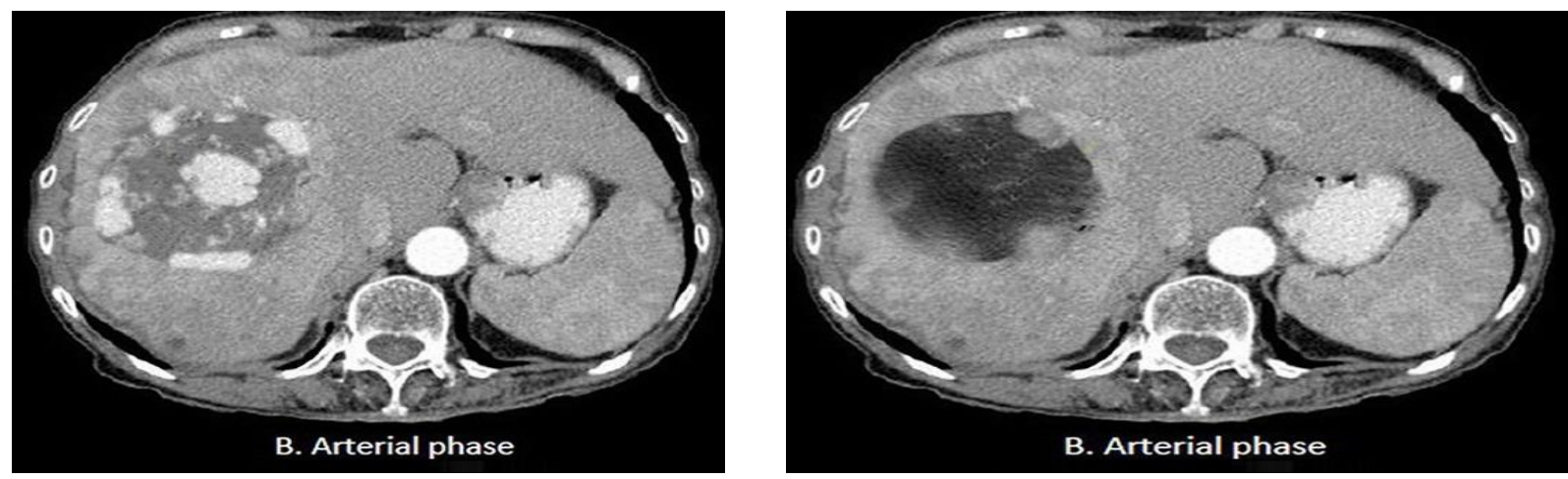

Figure (6): Triphasic CT scan (left) pre RFA+PEI shows a HCC (6x5.8cm). The 3-months CT scan (right) shows partial ablation of the lesion.

\section{DISCUSSION}

This study was conducted on $60 \mathrm{HCC}$ patients to test the effectiveness of two modalities on large lesions, 5.1-7 $\mathrm{cm}$ in the largest diameter. All the patients were Child A and this was a part of the inclusion criteria to achieve high success rate with the least complication. Males were predominant with a ratio of $5.7: 1$. This ratio is similar to that reported by Sherlock and Dooley [10] who pronounced male predominance of HCC throughout the world, on the order of 4:1 in low incidence area and up to 9:1 in high incidence areas. This ratio could be explained by hormonal factors as high testosterone level in males and methoxyestradiol in females [11]. The mean age was $60.3 \pm 8.6$ and this was slightly higher than some Egyptian studies conducted by Azab et al. [12], Salama et al. [13] and El-Kady et al. [14], probably because of the selection of patients, since the previous studies included patients with smaller lesions up to $5 \mathrm{~cm}$ compared to our study in which longer time was needed by the lesions to develop larger sizes. The mean age was slightly lower than the results of the Japanese and Italian patients conducted by Omata et al. [15] and Livraghi et al. [16] respectively. El-Zayadi et al. [17] reported that the average age of HCC patients was 60 years as was found in the study of Badawi and Michael [18]. The earlier age among Egyptians could be explained by the early age of acquisition of viral hepatitis (HCV and HBV) due to several factors can transmit infection among the population such as injections, circumcision and tattooing without proper sterilization [19].

In the present study AFP was positive in $73 \%$ of patients. In the follow up period the number of positive patients dropped to $20 \%$ and $15 \%$ one and three months later respectively. This was in agreement with Lawrence et al. [23] who stated that not all HCCs secrete AFP and approximately $30 \%$ of the patients had normal AFP levels. In the current study the post-procedural complications were mild that included abdominal pain in $18(60 \%)$ and $20(66.7 \%)$ and fever in $7(23.3 \%)$ and $9(30 \%)$ patients in GI and GII respectively. No significant statistical difference regarding complications in the two modalities in this study. Other complications including hematemesis, ascites were not observed. Livraghi et al. [16] reported hemothorax (2\%) due to damage of an intercostal vessel along the needle track, intraperitoneal bleeding, hemobilia and mild cholecystitis. Poon et al. [24] reported complications as segmental bile duct injury and multi-organ failure. In another study by Livraghi et al. [25], two major complications including massive bleeding from the liver capsule and death. However, both complications appeared largely attributable to surgeon error rather than to the RFA procedure itself. Complete ablation was achieved in $43(71.6 \%)$ of all $(60)$ patients; $18(60 \%)$ in GI compared to $25(83.3 \%)$ of GII, after 3 months as confirmed by triphasic CT with contrast. The difference was statically significant denoting better penetration of acetic acid as it destroys the fibrous septa present in the HCC. When the studied patients were stratified into subgroups A $(5.1-6 \mathrm{~cm})$ and $\mathrm{B}(6.1-7 \mathrm{~cm})$, ablation was significantly better in GII A than GI A $(86.6 \%$ vs $66.7 \%)$ and in G IIB than G IB ( $80 \%$ vs $46.7 \%)$ denoting that when acetic acid was added to RFA ablation was better than when ethyl alcohol was added indicating better diffusion to the unablated zones of the HCCs. There are few studies concerning combination therapies for large tumors, PAI alone was compared to RFA alone with medium and large-sized tumors, acetic acid showed comparable results $(76 \%$ vs $73.7 \%$ ) in a study conducted by El-Kady et al. [26]. Also the current

Nouh et al., Afro-Egypt J Infect Endem Dis 2019;9(2):129-138

https://aeji.journals.ekb.eg/

http://mis.zu.edu.eg/ajied/home.aspx 
results are similar to Poon et al. [24] who conducted the first study in which the effectiveness of RFA of HCCs 3.1 to $8.0 \mathrm{~cm}$ in diameter by means of a predominantly surgical approach was evaluated specifically. He demonstrated an overall complete ablation rate of $91 \%$ for HCCs 3.1 to $8.0 \mathrm{~cm}$ in diameter and $93 \%$ for HCCs 3.1 to $5 \mathrm{~cm}$. He assumed that radical ablation of large tumors is difficult to achieve percutaneously, even with repeated sessions. In the study conducted by ElKady et al. [26], PAI alone was used for medium and large-sized tumors ablated $76 \%$ of the lesions. When PAI was compared to PEI in tumors up to $6 \mathrm{~cm}$ in diameter, ablation was achieved in $86.7 \%$ and $66.7 \%$ respectively [5] . Combined therapies in smaller tumors up to $5 \mathrm{~cm}$ gave better results than in large tumors. In one study conducted by Azab et al., [27] using RFA plus PEI, 97\% of 33 lesions were ablated. In one study using RFA plus PAI ablation of large tumors $(5-8 \mathrm{~cm})$ conducted by Azab [28], ablation was achieved $46.6 \%$ compared to $20 \%$ in PAI alone. Another study using RFA plus PAI conducted by El-Sayed [29], ablation was achieved in $90 \%$ in lesion less than $5 \mathrm{~cm}$. Our results showed the superiority RFA plus PAI combination for large tumors ( $>5 \mathrm{~cm}$ and up to $7 \mathrm{~cm}$ in diameter). Acetic acid has the ability to penetrate cells with the property of extracting collagen and dissolving lipids has a stronger killing effect on hepatocytes than ethanol as reported by Okada [30]. However more studies are needed to evaluate different combinations and frequency of sessions on larger series of patients.

Funding: None.

\section{Conflicts of interest: None.}

Ethical approval:Approved .

\section{CONCLUSION}

Ablation of inoperable large $\mathrm{HCC} 5.1-7 \mathrm{~cm}$ can be done with combined techniques. RFA plus acetic acid was compared to RFA plus ethyl alcohol. Complete ablation was superior when acetic acid was used. This is probably due to the ability to penetrate cells with the property of extracting collagen and dissolving lipids leading to a stronger killing effect on hepatocytes. A study with larger number of patients and more frequent sessions of acetic acid injection after RFA may give better results.

\section{REFERENCES}

1. Choo SP, Tan WL, Goh BK, Tai WM, Zhu AX. Comparison of hepatocellular carcinoma in Eastern versus Western populations. Cancer 2016; 122: 3430-3436

2. Solbiati L, Goldberg SN, Ierace T, Dellanoce M, Livraghi T, Gazella GS. Radio-frequency ablation of hepatic metastases: postprocedural assessment with a US microbubble contrast agent-early experience. Radiology 1999; 211: 643-649.

3. Bruix J and Sherman M. Management of hepatocellular carcinoma: an update. Hepatology 2011, Vol. 53, No. 3

4. Grazi L, Ercolani G, Pierangeli F, Gaudio M, Cescon $\mathrm{M}$ and Cavallari. Improved results of liver resection for hepatocellular carcinoma on cirrhosis give the procedure added value. Ann Surg 2001; 234:71-78.

5. Azab MM, Zaki S, EL-Shetey AG, Abdel-Moty MF, Alnoomani NA, Gomaa AA, Abdel-Fatah S, et al. Evaluation of the efficacy and safety of combined use of Percutaneous Ethanol injection \& Radiofrequency ablation versus Radiofrequency alone in the treatment of HCC. Arab Journal of Gastroenterology 2011; 12: 113-118.

6. Camma C, Di Marco V and Casaril A.Treatment of hepatocellular carcinoma in compensated cirrhosis with radio-frequency thermal ablation (RFTA): a prospective study. J Hepatol 2005; 42: 535 - 540.

7. DeVera ME, Marsh JW and Gamblin TC . Comparison of Percutaneous and Surgical Approaches for Radiofrequency Ablation of Small and Medium Hepatocellular Carcinoma Invited Critique Arch Surg 2007; 142(12): 1143 1143.

8. Okoda S. Local ablation therapy for HCC. Semin. Liver Dis 1999; 19 (3): 323-328.

9. Azab MM, Abd El-Aal S, Abd El-Sattar H, Salah Sh, Abdel Hafize Rashed H, Negm $M$ et al. Comparative study between Percutaneous Acetic Acid injections and Percutaneous Ethanol injection in the management of HCC. AMJ 2009; vol 38(4) ; 913-924.

10. Sherlock S and Dooley J. Diseases of the liver and biliary system. $13^{\text {th }}$ edition, Blackwell Scientific Publications 2018. London, Edinburgh, Boston.

11. Akriviadis EA, Llovet JM, Efremidis SC, Shouval D, Canelo R, Ringe B et al. Hepatocellular carcinoma. Br J Surg 1998; 85: 1319-1331.

12. Azab MM, Elhakeem MS, Elsharkawy MK, ElShetey AG, Abo- Eldahab M . Evaluation of some non surgical techniques in mangment of HCC . AMJ 2008 ; vol (5) ;185-202. 
13. Salama H, Bassiouny M, Amer A, and El-Sherif KH. Serial alphafeto protein levels versus spiral computed tomography after radiofrequency ablation of hepatocellular carcinoma. 2003; MD Thesis. Tropical Medicine, Cairo University

14. El-Kady N, El Bendary M, El-Sherbiny W and Al-Diasty M. Medium and large sized Hepatocellular carcinoma: Acetic acid versus radiofrequency ablation 2011; MD thesis of Tropical Medicine. Faculty of Medicine, Mansoura University.

15. Omata M, Dan Y, Daniele B, Plentz R, Rudolph KL, Manns M, et al. Clinical features, etiology, and survival of hepatocellular carcinoma among different countries. Journal of Gastroenteroalogy and Hepatology 2002; 17 (Suppl.): 540-549.

16. Livraghi T, Goldberg SN, Lazzaroni S, Meloni F, Solbiati L and Gazelle GS. Small hepatocellular carcinoma: treatment with radio-frequency ablation versus ethanol injection. Radiology 1999; 210: 655-661.

17. El-Zayadi A, Abaza H, Shawky S, Mohamed MK, Selim OE and Badran HM. Prevalence and epidemiological features of hepatocellular carcinoma in Egypt -A single center experience. Hepatol Research. 2001, 19:170-179.

18. Badawi AF and Michael MS. Risk factors for hepatocellular carcinoma in Egypt :The role of hepatitis B viral infection and schistosomiasis. Anticancer Res. 1999, 10(5C):4565-9.

19. El-Serag HB. Epidemiology of Viral Hepatitis and Hepatocellular Carcinoma. Gastroenterology; 2012, 142:1264-1273.

20. Abdul-Ghafar Y, Seleem A, Tawfeek M, Habib NA, El-Masry R Bassyouni M and El-Toukhy M. Percutaneous ethanol injection in large size and multiple lesions of hepatocellular carcinoma. Two years follow up in 165 patients. Med. J. Cairo University; 2002, 7040 (suppll 11): 299304.

21. Soliman A. Predictive factors of response in the treatment of hepatocellular carcinoma by radiofrequency versus acetic acid injection. MD Thesis, Tropical Medicine, Cairo University, 2003.
22. El-Kady N, El Bendary M, El-Sherbiny W and Al-Diasty M. Medium and large sized Hepatocellular carcinoma: Acetic acid versus radiofrequency ablation. MD thesis of Tropical Medicine. Faculty of medicine, Mansoura University, 2011a.

23. Lawrence TS, Kessler ML, Robertson JM. 3-D conformal radiation therapy in upper gastrointestinal cancer. The University of Michigan experience. Front Radiat Ther Oncol. 1996, 29: 221-228.

24. Poon RT, Ho JW, Tong CS, Lau C, Ng IO and Fan ST. Prognostic significance of serum vascular endothelial growth factor and endostatin in patients with hepatocellular carcinoma. Br J Surg. 2004, 91: $1354-1360$

25. Livraghi T, Goldberg SN, Lazzaroni S, Meloni F, Ierace T, Solbiati L and Gazelle GS. Hepatocellular carcinoma: radiofrequency ablation of medium and large lesions. Radiology; 2000, 214(3):761-768

26. El-Kady N, El Bendary M, El-Sherbiny W and Al-Diasty M. Medium and large sized Hepatocellular carcinoma: Acetic acid versus radiofrequency ablation. MD thesis of Tropical Medicine. Faculty of medicine, Mansoura University, 2011a.

27. Azab MM, Zaki S, EL-Shetey AG, Abdel-Moty MF, Alnoomani NA, Gomaa AA, Abdel-Fatah S, Mohiy S and Atia F. Evaluation of the efficacy and safety of combined use of Percutaneous Ethanol injection \& Radiofrequency ablation versus Radiofrequency alone in the treatment of HCC. Arab Journal of Gastroenterology, 2011, 12: 113-118.

28. Azab HM. Study of the efficacy of combined radiofrequency ablation and percutaneous acetic acid injection in the management of hepatocellular carcinoma. MSc. Tropical Medicine. Faculty of medicine. Al-Azhar University, Cairo, 2010.

29. El-Sayed H. Comparative Study Between Radiofrequency Ablation Alone And If Combined with Percutaneous Acetic Acid Injection in The Treatment of Hepatocellular Carcinoma. MD thesis, Tropical Medicine. Faculty of medicine. Al-Azhar University, Cairo, 2012.

30. Okoda S . Local ablation therapy for HCC. Semin. Liver Dis. 1999, 19 (3): 323-328. 